\title{
The Relationship Between Lower Urinary Tract Symptoms and Osteoarthritis Symptoms Among Vendors in a Conventional Market
}

\author{
Hyo Jeong Song ${ }^{1}$, M. Danet Lapiz Bluhm², Moonju Lee'2 Hyung Jee Kim³ $^{3}$, Hong Sang Moon ${ }^{4}$ \\ ${ }^{1}$ College of Nursing, Jeju National University, Jeju, Korea \\ ${ }^{2}$ School of Nursing, University of Texas Health Science Center at San Antonio, San Antonio, TX, USA \\ ${ }^{3}$ Department of Urology, Dankook University College of Medicine, Cheonan, Korea \\ ${ }^{4}$ Department of Urology, Hanyang University College of Medicine, Seoul, Korea
}

\begin{abstract}
Purpose: This study aimed to investigate lower urinary tract symptoms (LUTS) and the correlation between LUTS and osteoarthritis (OA) symptoms in the vendors working in a conventional market.

Methods: This cross-sectional study was conducted on 153 vendors aged 40 and over from August 10th to September 8th, 2020, in a conventional market. Data were collected via the self-reported questionnaires. We assessed LUTS by International Prostate Symptom Score (IPSS) and OA symptoms by Western Ontario and McMaster Universities Osteoarthritis Index (WOMAC).

Results: The mean age of 153 subjects was $61.31 \pm 9.92$ years old. The mean score of IPSS and WOMAC was $5.37 \pm 5.68$ (range, $0-35$ ) and $16.89 \pm 19.61$ (range, $0-96$ ). Fifty-one percent of subjects had urinary incontinence at least monthly. Twenty-four point two percent of subjects had moderate-to-severe LUTS which were defined as a score of IPSS $\geq 8$. LUTS were positively correlated with $\mathrm{OA}$ symptoms $(\mathrm{r}=0.41, \mathrm{P}<0.001)$.

Conclusions: The results showed that LUTS were associated with OA symptoms, and it also emphasized the need for vendors to be provided with a health education program to manage and prevent their LUTS and OA symptoms.
\end{abstract}

Keywords: Lower urinary tract symptoms; Osteoarthritis; Occupation

- Fund/Grant Support: This work was supported by a research grant from Jeju National University in 2020.

- Research Ethics: The study was performed in accordance with the ethical standards of the Declaration of Helsinki. This study was approved by the institutional review board (approval number: JJNU-IRB-2020-031) of Jeju National University. All subjects provided written informed consent before participating in this study.

- Conflict of Interest: No potential conflict of interest relevant to this article was reported.

\section{INTRODUCTION}

The impact of lower urinary tract symptoms (LUTS) on individuals' everyday life can be significant, triggering distress and reduced confidence that may adversely affect work-related pro- ductivity and social interactions [1]. Reduced quality of life has been reported among individuals with LUTS, and many individuals experience bothersome symptoms that impair the quality of their daily life [2].

LUTS encompasses a wide range of symptoms, categorized

Corresponding author: Hong Sang Moon (i) https://orcid.org/0000-0003-2101-1019 Department of Urology, Hanyang University Guri Hospital, 153 Gyeongchunro, Guri 11923, Korea

Email: moonuro@hanyang.ac.kr

Submitted: April 25, 2021 / Accepted after revision: June 3, 2021 
by the International Continence Society (ICS) as bladder storage, voiding, and postmicturition symptoms. Storage symptoms include urinary frequency, nocturia, urinary urgency, and urinary incontinence (UI). Voiding symptoms include slow stream, intermittent stream, hesitancy, and straining [3].

Yoo et al. [4] reported a total prevalence of LUTS of $68.2 \%$, including $70.6 \%$ among men and $66.0 \%$ among women, according to the ICS definition in their study of 2,080 subjects aged 40 years or older. Przydacz et al. [5] assessed a population aged 40 years or older in a Western country and reported a prevalence of LUTS of $69.8 \%$ (66.2\% among men and $72.6 \%$ among women). Importantly, the definition of LUTS can vary among studies, influencing the results. Liu et al. [6] reported in their study of participants aged older than 40 years that the prevalence of LUTS, defined as the presence of at least moderate symptoms according to the International Prostate Symptom Score (IPSS), among the total study population was approximately 30\%; while, in a Korean study, the prevalence of LUTS characterized by moderate or greater symptoms per IPSS was higher in men (44.7\%) than in women (35.8\%) [4].

Osteoarthritis (OA) is also highly prevalent around the globe as a leading cause of disability that can negatively impact people's physical and mental well-being [7]. The knees and hips are the parts most affected by OA in general, leading to pain, stiffness, swelling, and loss of normal joint function [8]. The Western Ontario and McMaster Universities Osteoarthritis Index (WOMAC) is a widely used measure for assessing pain, stiffness, and physical function among people with OA of the knee and hip joints [9]. Moreover, mobility problems, including those symptoms caused by OA, might lead to a delay in urination at an appropriate time or trouble with using the toilet [10]. Previous research has shown that OA and OA pain are associated with UI [11], and Ahmadi et al. [12] also reported that OA increased the risk of UI.

On the other hand, occupation type and workplace environment may be closely related to the presence of voiding problems. Limited restroom use among workers may occur in the work environment due to an increased work burden, i.e., greater inconvenience when using the restroom at work [13]. Workers in service and retail occupations may not have adequate time for toileting due to high-paced job demands [14]. Moreover, occupations that demand characteristics such as awkward positioning, physically hard activities, and more manual labor are risk factors of LUTS and UI [15]. Several studies have assessed the prevalence of LUTS, including UI among women working in production facilities, teachers, and female air force members [16-18].

In Korea, community-based epidemiologic studies on LUTS have concluded that LUTS is associated with sociodemographic characteristics [19], lifestyle [20], and falls and/or a fear of falling [21]. Kim and Kwak [22] examined the association between UI in working women and their occupational status by using data from the fourth Korea National Health and Nutrition Examination Survey.

Vendors at the conventional market need to work on strenuous physical lifting and activities, knee-bending or squatting position, and prolonged standing posture all day long, which may lead to a higher risk of developing muscle joint problems and knee OA in particular [23]. However, there is little research on LUTS in specific occupational groups. such as conventional market vendors with limited restroom use and a significant daily musculoskeletal burden. Therefore, we aimed to investigate LUTS and the relationship between LUTS and OA symptoms among vendors working in a conventional market as one of the specific occupational groups that remains to be investigated. We also intended to provide basic data to support the development of an education program for the management of voiding and musculoskeletal health among vendors in a conventional market.

\section{MATERIALS AND METHODS}

\section{Design and Ethics Statement}

This study employed a cross-sectional design. The present study was conducted following the ethical standards of the Declaration Helsinki and was approved by the Institutional Review Board at Jeju National University (approval number: JJNUIRB-2020-031).

\section{Samples and Data Collection}

Data were collected via a self-reported questionnaire. A total of 153 individuals, who were all vendors aged 40 years and older working at a conventional market located in Jeju City, agreed to participate in the study with a full understanding of the purpose and the content of the study. Individuals who had a medical history of stroke and/or Parkinson disease were excluded. The first author provided details on the purposes, contents, and methods of the study to the chairman and directors of the Vendors Association and they agreed with data collection. Then, from August 10 through September 8, 2020, the author and/or 
research assistants visited each vendor's store. After explaining the study's purpose to each vendor, data were collected by their completion of the questionnaire, which took about 15 minutes per vendor. Vendors' participation in the study was voluntary and they were given a full explanation regarding discontinuing completion of the questionnaire at any time together with an assurance of confidentiality of their responses and personal information.

\section{Sample Size}

The sample size was computed using the $\mathrm{G}^{*}$ power 3.1 software [24]. With a statistical significance of 0.05 , a power of 0.95 , and an effect size of 0.3 , in the correlation, the sample size was found to be 134. Considering the potential for loss to follow-up, we distributed 160 questionnaires; 7 with incomplete data were eventually excluded, so 153 vendors were enrolled in this study.

\section{Questionnaire and Measures General characteristics}

Using the questionnaire, the study participants were asked about general characteristics, such as sex, age, educational level, marital status, alcohol consumption, smoking, regular exercise habits, and chronic diseases.

\section{Lower urinary tract symptoms}

LUTS were evaluated by the Korean version of the IPSS [25]. The IPSS includes 4 voiding LUTS (hesitancy, intermittency, weak stream, and incomplete emptying of the bladder) and 3 storage LUTS (frequency, urgency, and nocturia). Subjects were asked to indicate the frequency with which they experienced each of the 7 symptoms during the past 3 months on a scale of $0-5$. IPSS scores range from 0 to 35 ; scores ranging from 0 to 7 indicate mild LUTS, scores from 8 to 19 indicate moderate LUTS, and scores from 20 to 35 indicate severe LUTS. Positive LUTS was operationally defined as a score of IPSS $\geq 8$ of moderate-to-severe LUTS.

\section{Urinary incontinence}

UI was assessed on the basis of the definition of the ICS [5] as a "complaint of any involuntary leakage of urine," and UI was operationally defined as incontinence by the reporting of involuntary urine loss at least once per month during the 3 months prior to data collection. Stress UI symptoms were identified when the participant responded positively to the question, "have you had leakage of urine when you coughed, laughed, exercised, lifted, or climbed stairs during the past 3 months?" Urge UI was identified when the participant responded positively to the question, "during the past 3 months, when leakage of urine has occurred, were you aware of the need to urinate before the leakage occurred?" Mixed UI was confirmed when the participant responded positively to these 2 questions [26].

\section{OA symptoms}

The WOMAC, a self-reported questionnaire that includes 24 questions classified into 3 subscales of pain, stiffness, and physical function, was used to assess OA symptoms [27]. The WOMAC includes 5 questions on pain, 2 questions on stiffness, and 17 questions on physical function. Each question was scored on a 5 -point Likert scale format as none (0), mild (1), moderate (2), severe (3), or extreme (4). The score for each subscale is calculated by summing the component item scores for each subscale. Thus, the total score ranges are $0-96 ; 0-20$ for pain, $0-8$ for stiffness, and 0-68 for physical function.

\section{Statistical Analysis}

Statistical procedures were performed with the SAS ver. 9.2 (SAS Institute, Cary, NC, USA). Descriptive data were reported by using the mean, standard deviation, or frequency as indicated. To test the mean differences in the scores of LUTS by general characteristics and the mean differences in the scores of WOMAC by UI and LUTS severity, a Student t-test, or 1-way analysis of variance with post hoc test (Duncan test) was adopted. Pearson correlation coefficient was calculated to identify the relationship between LUTS and OA symptoms, and age was corrected as a covariate.

\section{RESULTS}

\section{General Characteristics}

A total of 153 participants were enrolled in this study, $77.8 \%$ of whom were female, with a mean age of $61.31 \pm 9.92$ years (range, $40-80$ years); 39.9\% of participants were aged 60 to 69 years and $18.3 \%$ were aged 70 years or older. Additionally, 23.5\% had completed elementary school, and 70.6\% were married. $9.8 \%$ of the participants drank alcohol regularly, and 7.2\% were current smokers. No regular exercise was reported by $50.3 \%$ of the participants, and $42.1 \%$ had chronic diseases (Table 1). 
Table 1. General characteristics of study participants $(n=153)$

\begin{tabular}{|c|c|}
\hline Characteristic & Value \\
\hline \multicolumn{2}{|l|}{ Sex } \\
\hline Male & $34(22.2)$ \\
\hline Female & $119(77.8)$ \\
\hline Age $(\mathrm{yr})$, mean $\pm \mathrm{SD}$ (range) & $61.31 \pm 9.92(40-80)$ \\
\hline $40-49$ & $25(16.3)$ \\
\hline $50-59$ & $39(25.5)$ \\
\hline $60-69$ & $61(39.9)$ \\
\hline$\geq 70$ & $28(18.3)$ \\
\hline \multicolumn{2}{|l|}{ Education level } \\
\hline Elementary school & $36(23.5)$ \\
\hline Middle school & $35(22.9)$ \\
\hline High school & $61(39.9)$ \\
\hline College and over & $21(13.7)$ \\
\hline \multicolumn{2}{|l|}{ Marital status } \\
\hline Single & $9(5.9)$ \\
\hline Married & $108(70.6)$ \\
\hline Divorce/widow & $36(23.5)$ \\
\hline \multicolumn{2}{|l|}{ Alcohol drinking } \\
\hline None & $84(54.9)$ \\
\hline Infrequently & $54(35.3)$ \\
\hline Regularly & $15(9.8)$ \\
\hline \multicolumn{2}{|l|}{ Smoking habit } \\
\hline None & $125(81.7)$ \\
\hline Previous & $17(11.1)$ \\
\hline Current & $11(7.2)$ \\
\hline \multicolumn{2}{|l|}{ Regular exercise habit } \\
\hline None & $77(50.3)$ \\
\hline 1-2 times a week & $49(32.0)$ \\
\hline 3-7 times a week & $27(17.7)$ \\
\hline \multicolumn{2}{|l|}{ Chronic diseases $(\mathrm{n}=152)$} \\
\hline No & $88(57.9)$ \\
\hline Yes & $64(42.1)$ \\
\hline
\end{tabular}

Values are presented as number (\%) unless otherwise indicated. $\mathrm{SD}$, standard deviation.

\section{LUTS and Severity, UI, and OA Symptoms}

The mean IPSS was $5.37 \pm 5.68$. Concerning the reported severity of LUTS, $20.9 \%$ of participants were included in the moderate group and $3.3 \%$ were included in the severe group according to their IPSS scores; thus, $24.2 \%$ of respondents with LUTS had moderate-to-severe symptoms (IPSS $\geq 8$ ). Among all symptoms of LUTS, nocturia garnered the highest score (1.51 \pm 1.04).
Table 2. Severity and each symptom of LUTS, UI, and OA symptoms $(\mathrm{n}=153)$

\begin{tabular}{|c|c|}
\hline Variable & Value \\
\hline \multicolumn{2}{|l|}{ Severity of the LUTS } \\
\hline Mild (IPSS range, 0-7) & $116(75.8)$ \\
\hline Moderate (IPSS range, 8-19) & $32(20.9)$ \\
\hline Severe (IPSS range, $\geq 20$ ) & $5(3.3)$ \\
\hline \multicolumn{2}{|l|}{ Each symptom score of the LUTS } \\
\hline Incomplete emptying of bladder & $0.60 \pm 1.02(0-5)$ \\
\hline Frequency & $0.70 \pm 1.08(0-5)$ \\
\hline Urgency & $0.73 \pm 1.03(0-5)$ \\
\hline Intermittency & $0.67 \pm 1.06(0-5)$ \\
\hline Weak stream & $0.73 \pm 1.17(0-5)$ \\
\hline Hesitancy & $0.43 \pm 0.92(0-5)$ \\
\hline Nocturia & $1.51 \pm 1.04(0-5)$ \\
\hline Total LUTS score & $5.37 \pm 5.68(0-35)$ \\
\hline \multicolumn{2}{|l|}{ UI/patterns } \\
\hline No UI & $75(49.0)$ \\
\hline Stress UI & $47(30.7)$ \\
\hline Urge UI & $2(1.3)$ \\
\hline Mixed UI & $29(19.0)$ \\
\hline \multicolumn{2}{|l|}{$\mathrm{UI} / \operatorname{sex}$} \\
\hline \multicolumn{2}{|l|}{ Male } \\
\hline No & $25(73.5)$ \\
\hline Yes & $9(26.5)$ \\
\hline \multicolumn{2}{|l|}{ Female } \\
\hline No & $50(42.0)$ \\
\hline Yes & $69(58.0)$ \\
\hline Osteoarthritis symptoms (WOMAC score) & $16.89 \pm 19.46(0-96)$ \\
\hline Pain & $3.41 \pm 4.16(0-20)$ \\
\hline Stiffness & $2.11 \pm 2.01(0-8)$ \\
\hline Physical function & $11.37 \pm 14.40(0-68)$ \\
\hline
\end{tabular}

Values are presented as number (\%) or mean \pm standard deviation (range). LUTS, lower urinary tract symptoms; UI, urinary incontinence; OA, osteoarthritis; IPSS, International Prostate Symptom Score; WOMAC, Western Ontario and McMaster Universities Osteoarthritis Index.

Fifty-one percent of all study participants had experienced UI more than once a month during the prior 3 months; more specifically, $49 \%$ had experienced no UI, 30.7\% had experienced stress UI, $1.3 \%$ had experienced urge UI, and $19.0 \%$ had experienced mixed UI. $26.5 \%$ of the male and $58.0 \%$ of the female subjects had UI.

The total WOMAC score of OA symptoms was $16.89 \pm 19.61$, and the following subscale scores were also recorded: pain, $3.41 \pm 4.16$; stiffness, $2.11 \pm 2.01$; and physical function, $11.37 \pm$ 
14.40 (Table 2).

\section{Differences in the Scores of LUTS by General Characteristics} LUTS was significantly different according to age $(\mathrm{F}=4.67, \mathrm{P}=$ $0.003)$ and marital status $(\mathrm{F}=4.03, \mathrm{P}=0.019)$. LUTS scores of those aged 70 years or older were significantly higher than those aged 40 to 49 years, 50 to 59 years, or 60 to 69 years. LUTS scores of participants who were divorced or widowed

Table 3. Differences in LUTS scores by general characteristics

\begin{tabular}{|c|c|c|c|}
\hline Characteristic & Mean \pm SD & tor F & $\mathrm{P}$-value \\
\hline Sex & & -0.09 & 0.931 \\
\hline Male & $5.24 \pm 4.99$ & & \\
\hline Female & $5.33 \pm 5.88$ & & \\
\hline \multicolumn{4}{|l|}{ Age (yr) } \\
\hline $40-49$ & $4.60 \pm 6.07^{\mathrm{a}}$ & 4.67 & $0.003^{*}(\mathrm{a}<\mathrm{b})$ \\
\hline $50-59$ & $4.90 \pm 4.32^{\mathrm{a}}$ & & \\
\hline $60-69$ & $4.30 \pm 4.50^{\mathrm{a}}$ & & \\
\hline$\geq 70$ & $8.85 \pm 7.94^{\mathrm{b}}$ & & \\
\hline Education level & & 1.14 & 0.334 \\
\hline Elementary school & $6.46 \pm 6.70$ & & \\
\hline Middle school & $5.94 \pm 6.92$ & & \\
\hline High school & $4.44 \pm 4.03$ & & \\
\hline College and over & $4.86 \pm 5.62$ & & \\
\hline Marital status & & 4.03 & $0.019^{*}(\mathrm{a}<\mathrm{b})$ \\
\hline Single & $4.67 \pm 2.18^{\mathrm{a}}$ & & \\
\hline Married & $4.59 \pm 4.34^{\mathrm{a}}$ & & \\
\hline Divorce/widow & $7.61 \pm 8.59^{\mathrm{b}}$ & & \\
\hline Alcohol drinking & & 2.28 & 0.106 \\
\hline None & $5.30 \pm 5.11$ & & \\
\hline Infrequently & $4.56 \pm 5.21$ & & \\
\hline Regularly & $8.07 \pm 9.06$ & & \\
\hline Smoking habit & & 0.02 & 0.981 \\
\hline None & $5.32 \pm 5.78$ & & \\
\hline Previous & $5.41 \pm 5.03$ & & \\
\hline Current & $5.0 \pm 5.92$ & & \\
\hline Regular exercise habit & & 0.59 & 0.554 \\
\hline None & $5.80 \pm 6.72$ & & \\
\hline 1-2 times a week & $4.71 \pm 4.55$ & & \\
\hline 3-7 times a week & $5.00 \pm 4.15$ & & \\
\hline Chronic diseases & & 1.05 & 0.295 \\
\hline No & $5.73 \pm 5.77$ & & \\
\hline Yes & $4.75 \pm 5.59$ & & \\
\hline
\end{tabular}

LUTS, lower urinary tract symptoms; SD, standard deviation. ${ }^{\star} \mathrm{P}<0.05$, Duncan test. were significantly higher than those of single or married participants (Table 3).

Differences in OA Symptom Scores by UI and LUTS Severity OA symptoms were significantly different according to UI $(\mathrm{t}=$ $-3.96, \mathrm{P}<0.001$ ), being statistically significantly higher among those with UI than among those without UI.

OA symptoms were also significantly different by LUTS severity $(\mathrm{F}=2.87, \mathrm{P}<0.001)$. According to LUTS severity, OA symptoms scores were the highest in the severe LUTS group (52.60 \pm 28.61), then lower in the moderate LUTS group (27.91 \pm 23.68$)$ and in the mild LUTS group $(12.12 \pm 14.48)$ (Table 4$)$.

\section{Correlation Between LUTS and OA Symptoms}

Pearson correlation coefficient showed that there was a significant, positive correlation between LUTS and OA symptoms $(\mathrm{r}=0.41, \mathrm{P}<0.001)$. In other words, the more severe the OA symptoms, the more severe the LUTS (Table 5).

\section{DISCUSSION}

The IPSS, which has been mostly used for evaluation purposes in previous epidemiological studies of LUTS in both men and

Table 4. Differences in the scores of OA symptoms (WOMAC score) by UI and LUTS severity

\begin{tabular}{lccc}
\hline Characteristic & Mean \pm SD & tor F & P-value \\
\hline UI & & -3.98 & $<0.001$ \\
No & $10.49 \pm 13.94$ & & \\
Yes & $22.36 \pm 22.10$ & & \\
LUTS & & 21.21 & $<0.001^{*}$ \\
& & & $(\mathrm{a}<\mathrm{b}<\mathrm{c})$ \\
Mild (IPSS range, 0-7) & $12.12 \pm 14.48^{\mathrm{a}}$ & & \\
Moderate (IPSS range, 8-19) & $27.91 \pm 23.68^{\mathrm{b}}$ & & \\
Severe (IPSS range, 20-35) & $52.60 \pm 28.61^{\mathrm{c}}$ & & \\
\hline
\end{tabular}

OA, osteoarthritis; WOMAC, Western Ontario and McMaster Universities Osteoarthritis Index; UI, urinary incontinence; LUTS, lower urinary tract symptoms; SD, standard deviation; IPSS, International Prostate Symptom Score.

${ }^{*} \mathrm{P}<0.05$, Duncan test.

Table 5. The relationship between LUTS and OA symptoms

\begin{tabular}{lc}
\hline Variable & r-value (P-value) \\
\hline OA symptoms & $0.41\left(<0.001^{\star}\right)$
\end{tabular}

LUTS, lower urinary tract symptoms; OA, osteoarthritis. ${ }^{\star} \mathrm{P}<0.05$, age as a covariate. 
women, is a valid, reliable, and sensitive measure to assess individuals of both sexes with LUTS and is a simple means for assessing the severity of LUTS $[28,29]$. In this study, IPSS was also used to evaluate LUTS and $24.2 \%$ of participants had LUTS defined as an IPSS score of at least 8 points (moderate and severe LUTS group). This result was lower than the prevalence of $30.1 \%$ reported by Liu et al. [6] among 2,068 subjects aged 40 years or older in Taiwan but was similar to the finding of $22.7 \%$ in the recent study of Przydacz et al. [5] of 6,005 subjects aged 40 years or older in a Western country. However, in a study of 2,080 subjects aged 40 years or older in Korea, a prevalence rate of $40.1 \%$ for LUTS defined by an IPSS of at least 8 points (moderate and severe group) was reported [4], which is much higher than the result of this investigation.

When considering each symptom of LUTS, nocturia garnered the highest score in this study. Similarly, in the study of Lee et al. [30] of subjects aged 19 years or older in Korea and that of Pinnock and Marshall [31] involving female and male residents in the community, nocturia was the most frequent and common symptom. Also, in a study of Taiwanese females, the most bothersome symptom was nocturia [6]. Nocturia is a symptom classified as one major component of common urologic conditions harbored by community-dwelling individuals. However, despite the higher prevalence, diverse etiology, and clinical importance of nocturia, management strategies for nocturia have not been designed successfully. Nakagawa et al. [32] reported from a 5-year observation period that communitydwelling elderly individuals with nocturia were at greater risk for fracture and death than those without nocturia. As such, we need further research on the assessment and management of nocturia, in particular among vendors at conventional markets. This study also showed that the LUTS score was significantly different by age and marital status. With participants aged 70 years or older having significantly higher scores than the other age groups (40-49, 50-59, and 60-69 years). In epidemiological studies by Lieberman et al. [33] and Terai et al. [28], LUTS based on IPSS score tended to increase with age. However, in this study, LUTS scores were similar across the fourth, fifth, and sixth decades of life, while the LUTS scores of those aged 70 years or older were significantly higher. Such a tendency might be because of the limitations of the study's sample representatives. Considering marital status, divorced or widowed participants had significantly higher LUTS scores than those who were single or married. This result suggests that environmental factors such as family structure and marital status have an impact on
LUTS score and severity. Divorced or widowed people may demonstrate a greater likelihood of neglecting their LUTS [19].

In this study, the subjects with UI showed a significantly higher LUTS score than the subjects without UI. Fifty-one percent of subjects had UI at least monthly, with $30.7 \%$ experiencing stress UI, 19.0\% experiencing mixed UI, and 1.3\% experiencing urge UI, respectively. As compared to the results in previous studies, which had defined UI definition in the same manner as done in this study, the prevalence of UI was $29 \%$ among production workers [16], 21\% among female air force members [18], and 38\% among nurses [34], our subject had UI at a relatively higher level. Stress UI was predominant; this finding is also similar to that of a previous study of UI types among nurses aged 21 to 59 years [17]. It can be assumed that stress UI may be precipitated by the physical demands of work (e.g., lifting, bending, and strenuous activity) of market vendors or nurses [14]. UI seriously degrades individuals' quality of life due to adversely affecting work efficiency and social life. Therefore, it is important for vendors to recognize that UI must be properly managed and prevented.

In our study, we did not investigate the severity of UI. Therefore, it should be needed to investigate the severity of UI, including the detailed UI frequency and the impact of UI on quality of life among vendors in further study.

The OA symptom scores of the group with UI were significantly higher than those of the group without UI. These results of this study support those of previous studies in which UI was reportedly related to $\mathrm{OA}$ and $\mathrm{OA}$ pain [11]. There are the specific characteristics of the conventional market that influence this result: toilets are often far away and there is a possibility that they may refrain from urinating because of customers who come by constantly. OA symptoms like pain, stiffness, and limited physical mobility could lead to UI in vendors who might have difficulty with getting to the toilet within a reasonable amount of time or with removing clothes quickly. Among the people with $\mathrm{OA}$, the inability to change one's posture to prevent stress UI is considered to cause stress UI [35].

In this study, a significant relationship was observed between LUTS and OA symptoms. It seems to be that the difficulty of going to the toilet in time to void due to OA symptoms and mobility problems may be attributed to LUTS, and vendors who have OA pain and other OA symptoms may be negligent in pursuing LUTS management and treatment. From our study results, we can assume that the alleviation of OA symptoms would bring about improvements in LUTS among vendors. In 
addition, there is a need for health education to manage and prevent these 2 health problems at the same time.

As prolonged sitting and standing postures may produce changes in the musculoskeletal and vascular milieu of the pelvis and lower extremity vasculature, which may cause LUTS [35], deeper investigations in the future focusing on the specific association between vendors' postures and OA and/or OA symptoms and of the impact on pelvic floor muscle and function should be considered.

Our study had several limitations. First, vendors were sampled from a single conventional market in one city and data collection was cross-sectional in its design. Determining the presence of LUTS and OA symptoms relied largely on answers to self-reported questionnaires, these conditions were not measured by objective methods, such as physical examination, diagnostic testing, or a physician's diagnosis; thus, symptoms might be underreported.

In conclusion, significantly higher LUTS scores among vendors in a conventional market were reported by those aged 70 years or older, those who were divorced or widowed, and those with UI. Also, the OA symptom score was significantly higher in the group with UI. This study showed that LUTS are significantly correlated with OA symptoms. The conventional market setting may allow for easy dissemination of health education to the vendors. To establish an intervention program for proper management and prevention of LUTS and OA symptoms, group education and individualized education may be required through vendors' meetings and/or education by using smartphones.

\section{ACKNOWLEDGMENTS}

We, the authors, give thanks to the Chairman, Mr. Won-Il Kim, and to Mrs. Hae-Rye Park of the Association of Jeju Dongmun Conventional Market for data collection. Especially, we appreciate Mr. In-Kyu Ha, Ms. Shi-Ja Choi, and Ms. Suzie Kim, who helped collect the article's data. This work was supported by a research grant from Jeju National University in 2020.

\section{AUTHOR CONTRIBUTION STATEMENT}

- Conceptualization: HJS, HSM

- Data curation: HJS

- Formal analysis: $H J S$

- Funding acquisition: HJS

- Methodology: HJS, MDB, ML, HJK, HSM
- Project administration: HJS

- Writing-original draft: $H J S$

-Writing-review \& editing: $H J S, M D B, M L, H J K, H S M$

\section{ORCID}

Hyung Ji Kim

0000-0002-7993-1881

Hong Sang Moon

0000-0003-2101-1019

\section{REFERENCES}

1. Suh J, Oh SJ, Cho SY. Comprehensive review of effective application of questionnaires for clinical research on lower urinary tract symptoms with tamsulosin and cultural adaptation to the Korean language. Int Neurourol J 2020;24:313-23.

2. Kim SK, Kim KH, Kim SH, Yoo SJ, Jeong YW, Kim SK, et al. Health-related quality of life in adult males with lower urinary tract symptoms. Qual Life Res 2019;28:2419-28.

3. Abrams P, Cardozo L, Fall M, Griffiths D, Rosier P, Ulmsten U, et al. The standardization of terminology of lower urinary tract function: report from the standardization sub-committee of the International Continence Society. Neurourol Urodyn 2002;21:167-78.

4. Yoo TK, Lee KS, Sumarsono B, Kim ST, Kim HJ, Lee HC, et al. The prevalence of lower urinary tract symptoms in population aged 40 years or over, in South Korea. Investig Clin Urol 2018;59:166-76.

5. Przydacz M, Golabek T, Dudek P, Lipinski M, Chlosta P. Prevalence and bother of lower urinary tract symptoms and overactive bladder in Poland, an Eastern European Study. Sci Rep 2020;10: 19819.

6. Liu SP, Chuang YC, Sumarsono B, Chang HC. The prevalence and bother of lower urinary tract symptoms in men and women aged 40 years or over in Taiwan. J Formos Med Assoc 2019;118(1 Pt 1): 170-8.

7. Vina EV, Kwoh CK. Epidemiology of osteoarthritis: literature update. Curr Opin Rheumatol 2018;30:160-7.

8. Kolasinski SL, Neogi T, Hochberg MC, Oatis C, Guyatt G, Block J, et al. 2019 American College of Rheumatology/Arthritis Foundation guideline for the management of osteoarthritis of the hand, hip, and knee. Arthritis Rheumatol 2020;72:149-62.

9. Bellamy N, Buchanan WW, Goldsmith CH, Campbell J, Stitt LW. Validation study of WOMAC: a health status instrument for measuring clinically important patient relevant outcomes to antirheumatic drug therapy in patients with osteoarthritis of the hip or knee. J Rheumatol 1988;15:1833-40.

10. Turner-Stokes L, Frank AO. Urinary incontinence among patients 
with arthritis--a neglected disability. J R Soc Med 1992;85:389-93.

11. Kim H, Yoshida H, Hu X, Saito K, Yoshida Y, Kim M, et al. Association between self-reported urinary incontinence and musculoskeletal conditions in community-dwelling elderly women: a crosssectional study. Neurourol Urodyn 2015;34:322-6.

12. Ahmadi B, Alimohammadian M, Golestan B, Mahjubi B, Janani L, Mirzaei R. The hidden epidemic of urinary incontinence in women: a population-based study with emphasis on preventive strategies. Int Urogynecol J 2010;21:453-9.

13. Reynolds WS, Kowalik C, Delpe SD, Kaufman M, Fowke JH, Dmochowski R. Toileting behaviors and bladder symptoms in women who limit restroom use at work: a cross-sectional study. J Urol 2019; 202:1008-14.

14. Markland A, Chu H, Epperson CN, Nodora J, Shoham D, Smith A, et al. Occupation and lower urinary tract symptoms in women: a rapid review and meta-analysis from the PLUS research consortium. Neurourol Urodyn 2018;37:2881-92.

15. Liu B, Wang L, Huang SS, Wu Q, Wu DL. Prevalence and risk factors of urinary incontinence among Chinese women in Shanghai. Int J Clin Exp Med 2014;7:686-96.

16. Fitzgerald ST, Palmer MH, Kirkland VL, Robinson L. The impact of urinary incontinence in working women: a study in a production facility. Women Health 2002;35:1-16.

17. Liao YM, Dougherty MC, Biemer PP, Boyington AR, Liao CT, Palmer $\mathrm{MH}$, et al. Prevalence of lower urinary tract symptoms among female elementary school teachers in Taipei. Int Urogynecol J Pelvic Floor Dysfunct 2007;18:1151-61.

18. Fischer JR, Berg PH. Urinary incontinence in United States air force female aircrew. Obstet Gynecol 1999;94:532-6.

19. Jo JK, Kim KS, Nam JW, Choi BY, Moon HS. Sociodemographic factors related to lower urinary tract symptoms in men: a Korean community health survey. Int Neurourol J 2017;21:143-51.

20. Kim KS, Jo JK, Lee JA, Choi BY, Moon HS. Do lifestyle factors affect lower urinary tract symptoms? results from the Korean community health survey. Int Neurourol J 2019;23:125-35.

21. Kim KS, Nam JW, Choi BY, Moon HS. The association of lower urinary tract symptoms with incidental falls and fear of falling in later life: The Community Health Survey. Neurourol Urodyn 2018; 37:775-84.

22. Kim Y, Kwak Y. Urinary incontinence in women in relation to occupational status. Women Health 2017;57:1-18.

23. Coggon D, Croft P, Kellingray S, Barrett D, McLaren M, Cooper C.
Occupational physical activities and osteoarthritis of the knee. Arthritis Rheum 2000;43:1443-9.

24. Cohen J. Statistical power analysis for the behavioral sciences. 2nd ed. Hillsdale (NJ): Lawrence Erlbaum Associates; 1988. p. 407-65.

25. Choi HR, Chung WS, Shim BS, Kwon SW, Hong SJ, Chung BH, et al. Translation validity and reliability of IPSS Korean version. Korean J Urol 1996;37:659-65.

26. Song HJ, Bae JM. Prevalence of urinary incontinence and lower urinary tract symptoms for community-dwelling elderly 85 years of age and older. J Wound Ostomy Continence Nurs 2007;34:53541.

27. Bae SC, Lee HS, Yun HR, Kim TH, Yoo DH, Kim SY. Cross-cultural adaptation and validation of Korean Western Ontario and McMaster Universities (WOMAC) and Lequesne osteoarthritis indices for clinical research. Osteoarthritis Cartilage 2001;9:746-50.

28. Terai A, Matsui Y, Ichioka K, Ohara H, Terada N, Yoshimura K. Comparative analysis of lower urinary tract symptoms and bother in both sexes. Urology 2004;63:487-91.

29. Hyun H, Park YW, Kwon YC, Cho BK, Lee JH. Relationships between chronic periodontitis and lower urinary tract symptoms/benign prostatic hyperplasia. Int Neurourol J 2021;25:77-83.

30. Lee YS, Lee KS, Jung JH, Han DH, Oh SJ, Seo JT, et al. Prevalence of overactive bladder, urinary incontinence, and lower urinary tract symptoms: results of Korean EPIC study. World J Urol 2011; 29:185-90.

31. Pinnock C, Marshall VR. Troublesome lower urinary tract symptoms in the community: a prevalence study. Med J Aust 1997;167: 72-5.

32. Nakagawa H, Niu K, Hozawa A, Ikeda Y, Kaiho Y, Ohmori-Matsuda $\mathrm{K}$, et al. Impact of nocturia on bone fracture and mortality in older individuals: a Japanese longitudinal cohort study. J Urol 2010; 184:1413-8.

33. Lieberman EG, Boone RM, Radoslovich S, Haj V, Hiratzka J, Marshall LM, et al. Prevalence of preoperative lower urinary tract symptoms in patients undergoing elective lumbar spine surgery. Spine 2018;43:E1152-6.

34. Matthews CA, Whitehead WE, Townsend MK, Grodstein F. Risk factors for urinary, fecal, or dual incontinence in the Nurses' Health Study. Obstet Gynecol 2013;122:539-45.

35. Norton PA, Baker JE. Postural changes can reduce leakage in women with stress urinary incontinence. Obstet Gynecol 1994;84:770-4. 